\title{
SIGNIFICANTLY HIGH INCIDENCE OF T-1654C POLYMORPHIC VARIATION IN THE PROTEIN C GENE PROMOTER REGION IN EARLY ONSET LEGG-CALVE' PERTHES DISEASE
}

\author{
Pokharel R K*, Fujii S*, Shiba R*, Matsuo M*
}

\section{ABSTRACT}

Inherited thrombophilia has been suggested as a cause of micro-thrombosis resulting in femoral head necrosis in Legg-Calve' Perthes Disease (LCPD). Protein C, hepatic zymogens, acts as a thrombotic agent and regulates the coagulation cascade. Genotype variations in the promoter region of the protein $C$ gene (T-1654C; A$1641 G$ \& A-1476T) have been reported to be associated with plasma protein $C$ levels and thrombotic risk.

In order to clarify any association of these polymorphic variations to LCPD, we analyzed the promoter region of gene for protein $C$ (from -1704 to -1198 nt) in 70 Japanese LCPD cases (8 early-onset \& 62 lateonset type) and 93 controls.

Results of direct sequencing of the protein $\mathrm{C}$ gene promoter region showed a significantly high incidence of T-1654C change in early-onset LCPD cases than among the late-onset LCPD and control groups. Our results, therefore, suggest a significant association between early onset LCPD and the T-1654C mutation in the protein $\mathrm{C}$ promoter region.

Key Words: Protein C gene promoter region polymorphism, micro thrombosis, early-onset LCPD.

\section{INTRODUCTION}

Legg-Calve' Perthes Disease (LCPD) is osteonecrosis of capital femoral epiphysis of paediatric group. Usual age of onset of LCPD is four to nine years but can occur anytime from 2 to 12 years. On the basis of age at the time of onset, LCPD has been grouped into early-onset and late-onset types suggesting their different pathogenesis. Cases with disease onset before the age of five years belong to the early-onset type. Higher percentage of female patients and bilateral involvement has been seen in younger age group. Higher magnitude of femoral head necrosis has been found among the patients with early-onset LCPD. ${ }^{1,2,3}$
Thrombophilia and hypofibrinolysis has been reported to be associated with LCPD. ${ }^{4,5,6,7,8,9}$ However, the precise mechanism is not yet clear. Recently many studies have been done at the genetic level to establish molecular bases for the cause of LCPD. However, general consensus has still to be developed.

G1691A mutation in the factor V gene has been reported to be one of the pathogenetic causes of LCPD in American population. ${ }^{15}$ However, we ${ }^{16}$ and Siegfried et a ${ }^{17}$ could not find any association between this mutation and LCPD in Japanese and European population respectively.

\footnotetext{
* Kobe University, School of Medicine International Center for Medical Research.

** Hyogo prefectural hospital for disabled children, "Nojigiku" Japan.

Address for correspondence : $\quad$ Dr. Rohit Kumar Pokharel

Kobe University, School of Medicine International Center for Medical Research

Email: rohit@healthnet.org.np, pokharelrohit@hotmail.com
} 
Protein $\mathrm{C}$ is a hepatic zymogen that acts together with protein $\mathrm{S}$ as a thrombolytic agent and regulates the coagulation cascade by inhibiting the action of activated factor $\mathrm{V}$ that is necessary to make thrombin from prothrombin (fig. 1). Promoter region of the protein $\mathrm{C}$ gene regulates the gene expression in the hepatocytes. Numbers of the polymorphic variation in the promoter region of the protein $\mathrm{C}$ gene have been reported. The T-1654C, A-1641G and A-1476T in the promoter region of the protein $\mathrm{C}$ gene have been reported to be associated with plasma protein $\mathrm{C}$ levels and thrombotic risk. Individuals with

Fig. 1 
$\mathrm{CC} / \mathrm{GG} / \mathrm{TT}$ genotype are at higher risk for thrombotic disorder $(10,11)$. T-1654C may be one of the important regulatory sites for gene expression.

\section{METHODOLOGY}

Cases: LCPD cases treated and attending the follow-up clinic at Hyogo Prefectural Hospital for Disabled Children, Nojigiku were requested to volunteer in this study. With consents of the patients and the parents, 70 cases were included in this study. There was no selection bias with regards to sex, race and age at onset or severity of the disorder. Detailed clinical evaluation of each patient was done and peripheral blood samples were taken. Average age of disease onset was 7.2 years, ranging from 2 years and 6 months to 14 years and 3 months. Out of 70 cases 30 had left, 34 had right hip involvement and 6 cases had bilateral hips involvement. Seven cases were girls and 63 boys. Father of one case had LCPD during childhood. Two cases had acetabular dysplasia during early infancy. Eight cases that developed LCPD before the age of 5 years are considered as the early onset type. Other 62 cases had onset after the age of 5 years and are grouped as late onset type. Control samples were collected from 93 Japanese peoples.

DNA extraction: Peripheral whole blood samples were collected either in EDTA or in heparin. Genomic DNA was extracted by GenTLE kit (Takara Shujo Co. Ltd. Osaka) or Phenol Chloroform method.
Analysis of gene for protein C promoter region:

PCR amplification: A primer set was designed to amplify a 507 bp fragment of the Protein $\mathrm{C}$ gene promoter region (1704 to -1198 nucleotides) encompassing the three polymorphism sites. 5'-ATGAGACCACATCTGTCAAGG-3' (nt.-1704 to -1684) as sense and 5'CAAACTGTCTGTTGGAATGGCC-3' (nt.-1198 to-1219) as antisense primers (Fig.2). The sense primer was tailed with sense M13 sequence. A final volume of 30 ul reaction mixture was prepared that contained about $150 \mathrm{ng}$ of gDNA, $60 \mathrm{pmol}$ of each primer, $45 \mathrm{mM}$ of each of the four deoxynucleotide triphosphates, 10X PCR buffer (100 mM Tris-HCL, $500 \mathrm{mM}$ $\mathrm{KCL}, 15 \mathrm{mM} \mathrm{MgCl2}$ ) and $0.5 \mathrm{U}$ of Taq Polymerase (Takara). The DNA amplifications were performed in following thermal conditions: after 7 minutes of denaturation at $94 \mathrm{C}$, the program consist of 35 cycles of 30 seconds denaturation at $94 \mathrm{C}, 1$ minute annealing at $59 \mathrm{C}$ and 2 minutes extension at $72 \mathrm{C}$. The reaction was stopped at $4 \mathrm{C}$ after 7 minutes of final extension at $72 \mathrm{C}$. Amplification of $507 \mathrm{bp}$ fragment was confirmed by electrophoresis in $2 \%$ agar-rose gel.

Direct sequencing of the amplified products: We performed direct cycle sequencing according to the dideoxynucleotide chain termination method following the instruction of the manufacturer- DNA sequencing kit (dye primer cycle sequencing core kit) by Gentle Biomedical group seta 3-4-1 Otsu, Shiga 520-21,JP.

Fig. 3 
